\title{
BMJ Open Mediation analysis for new recognition criteria, working hours and overwork- related disease: a nationwide ecological study using 11-year follow-up data in Taiwan
}

Sheng-Hsuan Lin, ${ }^{1}$ Meng-Ying Chou, ${ }^{1}$ Ro-Ting Lin ${ }^{\circledR 2}$

To cite: Lin S-H, Chou M-Y, Lin R-T. Mediation analysis for new recognition criteria, working hours and overwork-related disease: a nationwide ecological study using 11-year follow-up data in Taiwan. BMJ Open 2019;9:e028973. doi:10.1136/ bmjopen-2019-028973

- Prepublication history for this paper is available online. To view these files please visit the journal online (http://dx.doi. org/10.1136/bmjopen-2019028973).

Received 07 January 2019 Revised 14 June 2019 Accepted 11 July 2019
Check for updates

(C) Author(s) (or their employer(s)) 2019. Re-use permitted under CC BY-NC. No commercial re-use. See rights and permissions. Published by BMJ.

${ }^{1}$ Institute of Statistics, National Chiao Tung University, Hsinchu, Taiwan

${ }^{2}$ Department of Occupational Safety and Health, College of Public Health, China Medical University, Taichung, Taiwan

Correspondence to

Dr Ro-Ting Lin;

roting@ntu.edu.tw

\section{ABSTRACT}

Objectives Taiwan revised its criteria for overwork-related cerebrovascular and cardiovascular disease (CCVD) in 2010. A new definition of overwork increased the number of recognised cases. Meanwhile, actual average working hours decreased. We estimated the effects of the revised criteria on the number of overwork-related CCVD cases and the mediation effect through reduced working hours. Methods From the Labor Insurance of Taiwan, we collected data on the total number of overwork-related CCVD cases from 2006 to 2016 and average monthly working hours for 13 industry groups. We conducted causal mediation analysis to investigate the mechanism of the effect of new criteria on CCVD mediated by working hours.

Results From 2006 to 2016, 594 overwork-related cases of CCVD were recognised across 13 industry groups. After introducing the new criteria, overwork-related CCVD increased by 8.40 cases (per one million person-years) (95\% Cl 4.53 to 15.05), which resulted from a decrease of 1.54 (95\% Cl 0.22 to 3.82 ) cases due to reduced working hours (mediation effect) and an increase of $9.93(95 \% \mathrm{Cl}$ 5.24 to 18.17) cases related to the effect of the criteria change and other covariates excluding working hours (alternative effect).

Conclusions Working hours are an important mediator of the effect of policy on the rate of overwork-related CCVD. Introducing new criteria for recognising overwork-related disease might raise awareness and prompt reductions in working hours, which also help to reduce CCVD. Our findings suggest that understanding mediation effects is important to evaluating national health policies.

\section{INTRODUCTION}

Working overtime is an emerging occupational and public health issue in East Asian societies. ${ }^{1-3}$ Among adverse health effects linked to overwork, cerebrovascular and cardiovascular disease (CCVD) is a primary concern. In 2016, overwork-related CCVD accounted for $10 \%$ of total cases of occupational disease in Taiwan (including death,
Strengths and limitations of this study

- The main strength of the study is that it contributes to the estimation of relative importance of working hours in mediating the effect of new criteria on the rate of overwork-related cerebrovascular and cardiovascular disease (CCVD) using causal mediation analysis.

- We collected data on the number of overwork-related CCVD cases and average monthly working hours for 13 industry groups from 2006 to 2016.

- Data during these 11 years showed that the number of overwork-related CCVD cases increased after introducing new criteria, and that this effect was mediated by the decrease in working hours.

- Extrapolation to individual effects or long-term cumulative effects of the policy change on the rate of overwork-related CCVD and working hours are not the focus of this study.

- Our findings may assist in uncovering the causal mechanism underlying the impacts of policy change on working hours and overwork-related disease.

disability and illness), but up to $81 \%$ of the total number of occupational deaths. ${ }^{4}$

Establishing policy is a key step to eliminating exposure to overwork and preventing overwork-related disease. ${ }^{56}$ Sound national policies, such as labour standards and occupational health regulations, have been regarded as cornerstones of protecting workers' rights to health and the primary force pushing employers to provide decent jobs. ${ }^{5}$ To effectively prevent overwork-related disease, national policies and guidelines must first recognise that these diseases are attributable to occupational factors and working conditions, ${ }^{7}$ such as prolonged working hours. Second, national policies and guidelines need to address both to what extent they can change the overall working environment (including specific risk factors, such 
as maximum working hours and minimum wage) and to what extent these changes will prevent disease. ${ }^{9}$ Policies and guidelines at the national level can harmonise basic practices across industries and further eliminate gaps in exposure to various risk factors for overwork-related disease. $^{1011}$

In 2010, the government of Taiwan revised its recognition guidelines for overwork-related CCVD to further protect workers' interests and to respond to various stakeholders' demands following the high-profile death of a young engineer who had worked more than 295 hours in the month before his death. ${ }^{12}$ Taiwan's recognition guidelines are now the same as those implemented in Japan in $2001 .^{2}$

We have previously argued that the introduction of new recognition criteria for overwork-related CCVD in Taiwan led to a 2.6-fold increase in the rate of recognised overwork-related CCVD, by comparing Taiwan's policy transformation with that in Japan in 2001. ${ }^{13}$ The key change in the new criteria was lowering the overtime criteria by 8 hours. Prior to 2010, the number of regulatory maximum working hours was 84 hours every 2 weeks, and a case would be recognised as overwork-related if it involved overtime work that exceeded (1) 100 overtime hours during the month prior to disease onset, (2) an average of 80 overtime hours per month during the second to sixth months prior to onset or (3) an average of 45 overtime hours per month for 6 months prior to onset. Since the new criteria were implemented, these numbers have been changed to (1) 92 overtime hours in prior month, (2) 72 overtime hours per month during the second to sixth months and (3) 37 overtime hours per month in the prior 6 months. Moreover, according to the new recognition criteria, the burden of proof shifts to the employers to prove the employees do not work overtime. ${ }^{12}$ This change could raise employers' awareness on the importance of reducing working hours, but also provide society with a reference limit on overtime working hours in a quantitative way. To what extent the new criteria contributed to changing the rates of recognised overwork-related CCVD through working hours, however, remained unexplored.

To investigate the mechanisms by which the new criteria on working hours affected the recognition rate, several analytic methods have been proposed, including causal mediation analysis, path analysis and structural equation modelling. ${ }^{14}$ Causal mediation analysis, based on causal theory and counterfactual outcome models, is a generalised form of all above methods. ${ }^{14}{ }^{15}$ Causal mediation analysis can identify whether specific mediators are indeed important in a mechanism. Such an analysis can form a basis for developing more effective strategies for preventing disease and help policymakers select appropriate policy measures.

Therefore, in this study, we conducted a causal mediation analysis to investigate the degree to which Taiwan's 2010 change in overtime criteria increased the rate of recognised overwork-related CCVD, and how that effect was mediated by actual reductions in working hours. We hypothesised that the introduction of the new criteria would increase the rate of recognised overwork-related disease but that the rate would be offset by the decreased working hours resulting from the new criteria. We focused on investigating how working hours varied following the policy change and also estimated the mediation and alternative effects of the change on the rate of overwork-related CCVD.

\section{METHODS}

Our unit of study was the industry sector, so we used an ecological study design to conduct the longitudinal mediation analysis. We defined industry sector based on the Standard Industrial Classification System of Taiwan, 10th revision, which uses 19 industry sectors. We excluded three sectors (ie, agriculture, forestry, fishing and animal husbandry; education; and public administration and defense/compulsory social security) because they did not offer complete data (ie, number of CCVD cases, working hours, salary and unemployment) for analysis. We classified the remaining 16 sectors into 13 industry groups because only group-level data were available for longitudinal analysis. ${ }^{16}$ The industry groups used in the analysis are as follows: (1) mining and quarrying; (2) manufacturing; (3) electricity and gas supply, water supply and remediation activities; (4) construction; (5) wholesale and retail trade; (6) accommodation and food service activities; (7) transportation and storage, information and communication; (8) finance and insurance activities; (9) real-estate activities; (10) professional, scientific and technical activities; (11) human health and social work activities; (12) arts, entertainment and recreation and (13) support service activities, other service activities.

The study outcome was the number of overwork-related CCVD cases that were recognised and compensated by the government based on the 2010 criteria. $^{12}$ According to those criteria, occupational physicians should evaluate each case for the contribution of quantitative occupational indicators (eg, working hours), qualitative occupational factors (eg, indicators of working stress) and personal characteristics (eg, gender, health behaviours) prior to the onset of disease. Occupational physicians then weigh the contribution of the various factors and decide whether the case is attributable mainly to occupational or to personal factors. Among the occupational factors, the number of working hours is the indicator that historically has been most accessible to occupational physicians making this decision. The 2010 criteria significantly reduced the number of working hours required to count as overtime. Attention to working hours also can be used to examine whether employers reduced total working hours after the introduction of the 2010 criteria.

In this study, we obtained annual data on the number of person-cases of illness, disability and death resulting from overwork-related CCVD in each industry group. Data came from the Bureau of Labor Insurance, Ministry of Labor of Taiwan. ${ }^{4}$ We also collected data on the number of 
hired employees who received a salary or other economic compensation in each industry group. ${ }^{17}$ Then, we calculated the rate of overwork-related CCVD by dividing the total numbers of disease cases by the total number of employees for each industry group in each year.

The primary exposure measure was the implementation of the new recognition criteria in 2010. The mediator of interest was total working hours-the sum of the average number of regular working hours by industry group and the number of overtime working hours. Other covariates-salary and unemployment rate-were used as baseline covariates, and have been discussed in a previous paper. ${ }^{13}$ We obtained data on working hours, salary and unemployment rates for each industry sector from the Ministry of Labor of Taiwan. ${ }^{17}$

Taiwan had its first recognised case of overwork-related CCVD in 2006. The study period was from 2006 through 2016. ${ }^{4}$ During these 11 years, there were 594 accumulated number of cases of overwork-related CCVD under the labour insurance scheme across the 13 industry groups. ${ }^{417}$

\section{Patient and public involvement}

There was no patient or public involvement because our study involved comparison and analysis of variables at the population level (industry groups) rather than at the individual level. No personal data were handled.

\section{Statistical analysis}

We conducted a causal mediation analysis to investigate the role of working hours in the mechanism by which the new recognition criteria resulted in increased numbers of recognised overwork-related CCVD. ${ }^{15}$ We assumed causal relationships among the criteria's implementation status, the number of overwork-related CCVD cases and the average number of working hours, as shown in figure 1 . The total effect of the new criteria on disease was divided into two parts: (1) the part involving the change in working hours (mediation effect or natural indirect effect) and (2) the part not involving that change (alternative effect or natural direct effect).

For the industry sector $i$, where $i=1,2, \ldots, 13$, we built the following two regression models for the number of CCVD cases and working hours, respectively:

$\log E[$ number of casesl criteria,

$$
\begin{aligned}
& \text { working hours, salary, unemployment] } \\
& =\beta_{0}+\beta_{1} \times \text { criteria }+\beta_{2} \times \text { working hours } \\
& +\beta_{3} \times \text { salary }+\beta_{4} \times \text { unemployment } \\
& +\log \text { (cases per person-year) }+b_{0 i} \\
& E \text { [working hourslcriteria, salary, unemployment] } \\
& =\theta_{0}+\theta_{1} \times \text { criteria }+\theta_{2} \times \text { salary } \\
& +\theta_{3} \times \text { unemployment }+t_{0 i}
\end{aligned}
$$

In these models, $b_{0 \mathrm{i}}$ and $t_{0 \mathrm{i}}$ denote the random effect of intercepts for each model. Since the number of CCVD cases is a count variable and proportional to annual number of employees, which varied every year, the annual number of employees was the offset variable in the Poisson regression model.

In addition to causal mediation analysis, we conducted two traditional methods of mediation analysis-difference method and product method. The difference method is popular in the field of epidemiology and the product method is more popular in the social sciences. ${ }^{15} 1819$ Under some situations, such as a linear regression model without interaction terms, the difference method and the product method both provide valid estimations of a mediation effect. In most epidemiological and health-related studies, however, the outcomes of interest include categorical variables, such as dichotomous or counting data, and the statistical analysis requires nonlinear models (such as the logistic regression model and Poisson regression

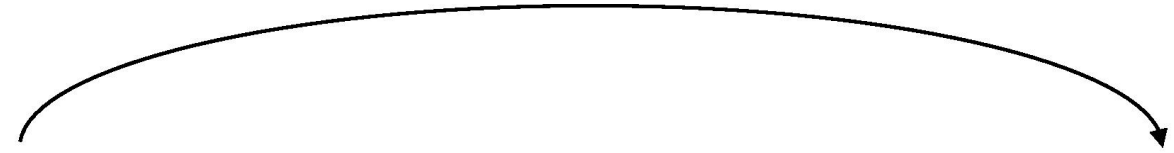

\section{Recognition criteria}

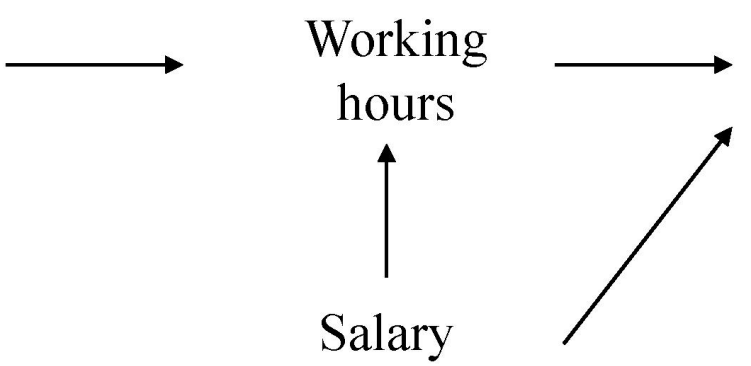

Overwork-related cerebrovascular and cardiovascular disease

\section{Unemployment}

Figure 1 Causal relationship among recognition criteria, working hours, overwork-related CCVD and potential confounders. It is assumed that recognition criteria is not affected by any factors, and that salary and unemployment are the only two confounders among working hours and CCVD, which are not affected by recognition criteria. CCVD, cerebrovascular and cardiovascular disease. 
Table 1 The averages for indicator characteristics across the 13 industry groups before and after implementation of 2010 recognition criteria for overwork-related CCVD

\begin{tabular}{|c|c|c|c|c|c|c|c|c|}
\hline \multirow[b]{2}{*}{ Indicator } & \multicolumn{4}{|c|}{$\begin{array}{l}\text { Before criteria } \\
(2006-2010)\end{array}$} & \multicolumn{4}{|c|}{$\begin{array}{l}\text { After criteria } \\
\text { (2011-2016) }\end{array}$} \\
\hline & Mean & Minimum & Maximum & SD & Mean & Minimum & Maximum & SD \\
\hline $\begin{array}{l}\text { Working hours per } \\
\text { month }\end{array}$ & 178.63 & 167.10 & 196.55 & 6.79 & 175.25 & 162.30 & 194.75 & 7.23 \\
\hline $\begin{array}{l}\text { Unemployment rate } \\
\text { (\%) }\end{array}$ & 4.52 & 1.34 & 13.82 & 2.32 & 3.96 & 1.31 & 14.01 & 1.94 \\
\hline $\begin{array}{l}\text { Overwork-related } \\
\text { CCVD case }\end{array}$ & 2.15 & 0 & 13 & 3.15 & 5.82 & 0 & 30 & 7.75 \\
\hline
\end{tabular}

CCVD, cerebrovascular and cardiovascular disease.

model).$^{20}$ In such cases, only causal mediation analysis provides valid estimations, but the difference method and product method can both offer intuitive results about the causal mechanism. We therefore also demonstrate and discuss the results of these two methods as a complement to causal mediation analysis.

All analyses were performed using R V.3.3.2. Causal mediation analysis is conducted by the mediation $\mathrm{R}$ package, developed by Tingley et al. ${ }^{21}$

\section{RESULTS}

Table 1 shows the averages for study indicators across the 13 industry groups before and after the implementation of the new criteria. The average number of employees increased by $11 \%$, from 525631 before the new criteria to 583487 after the new criteria. This increase in employees corresponded with a decrease in the unemployment rate, from $4.52 \%$ to $3.96 \%$. In addition, the average salary increased by $0.8 \%$, from 48580 New Taiwan dollars to 48958 New Taiwan dollars. In contrast, the average number of working hours decreased by 3.38, from 178.63 hours per month to 175.25 hours per month.

Table 2 shows the maximum likelihood estimates for the coefficients $\beta_{0}, \beta_{1}, \beta_{2}, \beta_{3}$ and $\beta_{4}$ in two models: one with and one without working hours as the independent variable. In the model without working hours, implementation of the 2010 criteria is significantly associated with the CCVD rate $\left(\beta_{1}=0.96,95 \%\right.$ CI 0.75 to 1.17$)$. When the model is conditioned on working hours, the coefficient for criteria implementation increases to 1.05 (95\% CI 0.83 to 1.27). Working hours are also a significant predictor of the CCVD rate $\left(\beta_{2}=0.23,95 \%\right.$ CI 0.05 to 0.41$)$.

Table 3 shows the maximum likelihood estimates for the coefficients $\theta_{0}, \theta_{1}, \theta_{2}$ and $\theta_{3}$ in a model that uses working hours as the dependent variable. The 2010 recognition criteria are significantly associated with working hours by a factor of -0.45 (95\% CI -0.59 to -0.32$)$. This means that the implementation of the new criteria decreased the average monthly working hours across industry groups by 0.45 hours.

The result of the causal mediation analysis is shown in table 4 . The total effect of implementing the new criteria was an increase in overwork-related CCVD of 8.4 cases (per one million person-years) (95\% CI 4.53 to 15.05). The total effect was further decomposed into the effect mediated by working hours (mediation effect) and the effect not mediated through working hours (alternative effect). The alternative effect shows that when not considering the actual reduction in average working hours, the implementation of the new criteria increased the diagnosed number of overwork-related CCVDs by 9.93 cases

Table 2 Coefficient estimations in models with and without working hours as the independent variable

\begin{tabular}{|c|c|c|c|c|c|c|c|c|}
\hline & \multicolumn{4}{|c|}{ Model without working hours } & \multicolumn{4}{|c|}{ Model with working hours } \\
\hline & Estimate & Lower $95 \% \mathrm{Cl}$ & Upper $95 \% \mathrm{Cl}$ & $P$ value & Estimate & Lower $95 \% \mathrm{Cl}$ & Upper $95 \%$ Cl & $P$ value \\
\hline Intercept $\left(\beta_{0}\right)$ & -13.11 & -13.86 & -12.37 & $<0.001$ & -13.15 & -13.85 & -12.44 & $<0.001$ \\
\hline Working hours $\left(\beta_{2}\right)$ & - & - & - & - & 0.23 & 0.05 & 0.41 & 0.014 \\
\hline Salary $\left(\beta_{3}\right)$ & 0.05 & -0.43 & 0.53 & 0.851 & 0.12 & -0.31 & 0.56 & 0.579 \\
\hline
\end{tabular}


Table 3 Coefficient estimations in a model using working hours as the dependent variable

\begin{tabular}{lcccc}
\hline & Estimate & Lower 95\% Cl & Upper 95\% Cl & P value \\
\hline Intercept $\left(\theta_{0}\right)$ & 0.20 & -0.33 & 0.73 & 0.465 \\
Criteria change $\left(\theta_{1}\right)$ & -0.45 & -0.59 & -0.32 & $<0.001$ \\
Salary $\left(\theta_{2}\right)$ & -0.28 & -0.63 & 0.06 & 0.105 \\
Unemployment $\left(\theta_{3}\right)$ & 0.01 & -0.05 & 0.07 & 0.689 \\
\hline
\end{tabular}

(per one million person-years) (95\% CI 5.24 to 18.17 ). However, the change in working hours following the new criteria led to a decrease of 1.54 cases (per one million person-years) (95\% CI 0.22 to 3.82). This was the mediation effect, which moved in the opposite direction from the total and alternative effects.

As a complement to causal mediation analysis, difference methods and product methods can be conducted based on the results in tables 2 and 3. In table 2, the coefficient of criteria change in the model without working hours represents the total effect, while the same coefficient under the model with working hours represents the alternative effect. The difference between the two coefficients is then used to estimate the mediation effect. Because the alternative effect is higher than the total effect, the mediation effect must have an opposite direction, and this is consistent with the conclusion from causal mediation analysis. According to the product method, the mediation effect is represented by the product of the coefficient of working hours on CCVD rates $(0.23$, see table 2$)$ and the coefficient of criteria change on working hours $(-0.45$, see table 3$)$. The former coefficient can be interpreted as long working hours leading to increased incidence of CCVD, while the latter coefficient represents the introduction of new criteria leading to a decrease in working hours. The result is that the criteria change decreased working hours and the reduction in working hours reduced the incidence of CCVD. The product method thus provides the intuitive direction of the mechanism by which the policy change led to changes in disease incidence.

\section{DISCUSSION}

Effective policies are needed to achieve the goal of preventing overwork-related disease. Our application of causal inference at the national level contributes to an understanding of the potential mediation effects related to quantitative outcomes of policy changes. Through our mediation analysis using an ecological dataset, we were able to detect a significant mediation effect of working hours on the association between the 2010 criteria change and overwork-related CCVD cases among industry groups.

Our findings show that the overall effect of the implementation of new recognition criteria in Taiwan increased recognised overwork-related CCVD by 8.4 cases (per one million person-years), which resulted from a decrease of 1.54 cases due to reduced working hours and an increase of 9.93 cases related to the overall effect of the criteria change and other covariates excluding working hours. That the implementation of new criteria in Taiwan led to an increase in overwork-related CCVD was consistent with previous analyses. ${ }^{1316}$ The new criteria lowered the limit for overtime by 8 hours. This means that a worker who develops cerebrovascular or cardiovascular disease today, following the same total working hours as a worker who developed disease prior to 2010, is now more likely to be recognised and compensated for overwork-related illness. This change in the criteria was intended to increase the rate of recognition of overwork-related disease, and to encourage employers to reduce the hours of overtime work required of their employees.

We also found that the new criteria can help reduce the number of working hours at the industry level, with an average decrease of 0.45 hours per month across studied industry groups in Taiwan. It should be noted that our unit of analysis was the industry sector, so we carefully interpreted results at the group level only. To capture workers potentially exposed to overtime working hours and at risk of overwork-related disease, we used the number

Table 4 Estimation for all effects of the 2010 recognition criteria on the rate of overwork-related cerebrovascular and cardiovascular disease

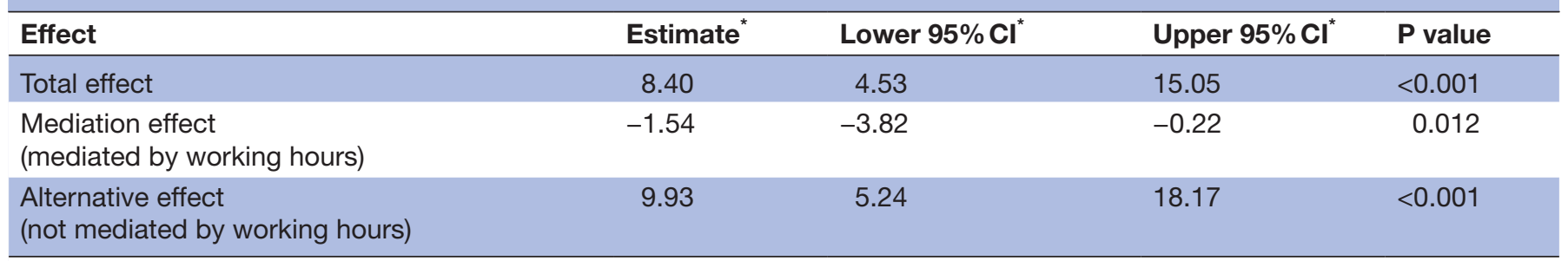

*The unit is 'case per one million person-years'. 
of hired employees as the denominator in our model. According to one previous study of long working hours, Taiwanese men who worked more than 60 hours per week had a 2.2-fold higher risk of coronary heart disease than those who worked $40-48$ hours per week. ${ }^{22}$ Those who worked 48-60 hours per week had a 1.6-fold higher risk than those who worked $40-48$ hours per week. ${ }^{22}$ Thus, any policy that leads to the reduction of working hours would help prevent overwork-related CCVD, and vice versa. ${ }^{23}$ Similarly, changes in mediators (such as working hours) may affect the apparent effectiveness of a policy. Our study provides evidence to support the hypothesis that Taiwan's introduction of new recognition criteria decreased overwork-related CCVD cases through a corresponding decrease in average working hours, even while the overall impact of the policy change was an increase in the rate of overwork-related CCVD due to a lower bar for recognising (and compensating) such disease. ${ }^{13} 16$

Today, Japan, Korea and Taiwan are the only three countries in the world that recognise long working hours as risk factors for overwork-related CCVD eligible for compensation. ${ }^{2}$ We previously found that implementing the new recognition criteria led to greater numbers of recognised overwork-related CCVD in both Japan and Taiwan. ${ }^{24}$ However, the total number of hours worked, due to its clear-cut definition, remains the main factor used to judge whether a CCVD is overwork-related or not. $^{2}$ Other factors, such as irregular work patterns and shift work or night work, should also be addressed. Korea's criteria, for instance, adopt different weights for the number of working hours on the night shift. ${ }^{225}$ Due to different recognition criteria, Korea has recognised a higher number of overwork-related disease than Japan or Taiwan. ${ }^{26}$ Taiwan's recognition criteria adopted the same criteria as Japan's, but placed less emphasis on shift work or night work. ${ }^{2}$ In contrast, the Korean criteria apply different weights for night shift hours and could be a model for future policy in Taiwan. ${ }^{2}$

On the other hand, while Japan enforced a new national act (Act on Promotion of Preventive Measures against Karoshi and other Overwork-Related Health Disorders) in 2014 to promote measures for preventing overwork, ${ }^{27}$ and has since seen average working hours decrease, ${ }^{28}$ Taiwan and Korea continue to record particularly long working hours. Compared with other Asian countries in the Organisation for Economic Co-operation and Development, Korea and Taiwan have ranked either first or second for the longest average working hours per year for the past 10 years. ${ }^{28}$ Given the current environment in Taiwan, we suggest the following issues that can inform future research. First, other national policies to reduce working hours will also be important for reducing the burden of overwork-related disorders. Future studies can use our methods to investigate the mediation effects of other regulations pertaining to overwork, such as the Occupational Safety and Health Act and the Labor Standards Act. Second, the continuing overwork issues in these three countries suggest a need to investigate how changes in policies affect the burden of overwork-related disease in different countries. A comparison of these countries' experiences can provide valuable insight into the development of national policies towards overwork prevention.

\section{Limitations about methodological issue}

Several study limitations about methodological issues are worth noting before making inferences from the results. First, it is impractical to conduct randomised experiments on the effect of criteria or policy changes on individuals, and differentiating the impacts of such events is difficult. ${ }^{17} 29$ Natural experimental and quasi-experimental designs can be alternatives to randomised experiments. However, most occupational health policy changes apply to a whole population. Our ecological study used ecological variables (ie, criteria change, average working hours by industry, average salaries by industry and average unemployment rates by industry) to estimate the effects on an ecological outcome variable (ie, overwork-related CCVD rates by industry). It is thus important to interpret the results at the group level rather than at the individual level. ${ }^{30}$ To capture workers who are potentially exposed to overtime working hours and at risk of overwork-related disease, we used the number of hired employees as the denominator in our model. Second, we analysed data that measured annual changes over an 11-year period. The autocorrelation among different measurements within the same industry group has been adjusted by building mixed-effect models. For simplicity, we assumed that there were no long-term cumulative effects of the policy change on the rate of overwork-related CCVD or working hours, as well as no long-term effects of the working hours changes on the rate of recognised disease. Some advanced statistical techniques, such as mediational g-formula, could be adapted in future research to release this assumption. ${ }^{3132}$

Finally, it will be important in the future to address our unmeasured confounding assumptions among criteria, working hours and CCVD. Here, we assume that the policy-making of criteria was not affected by all ecological factors. Furthermore, only the unemployment rate and salary were controlled as potential confounders between CCVD and working hours. ${ }^{3334}$ Both potential confounders were also assumed not to be affected by criteria in order to obtain causal interpretation. According to the recognition criteria, personal characteristics, such as lifestyle factors, should be evaluated and excluded during the process of recognising a CCVD as overwork-related for the labour insurance system. ${ }^{12}$ Only occupational factors listed in the recognition criteria, such as overtime working hours, are evaluated and recognised as risk factors for developing overwork-related CCVD. ${ }^{12}$ Therefore, our results should be less biased from the lack of data on lifestyle factors. More ecological covariates should be collected and adjusted to ensure the appropriateness of the unmeasured confounding assumption in future studies. 


\section{CONCLUSION}

Working hours are an important mediator of the effect of policy on the rate of overwork-related CCVD. Introducing new criteria for recognising overwork-related disease might raise awareness and prompt reductions in working hours, which also helps to reduce CCVD. Our findings suggest the importance of attention to changes in working hours when governments introduce new national policies and criteria. Our mediation analysis helps to uncover the causal mechanism underlying the impacts of policy change on working hours and overwork-related disease.

Acknowledgements We acknowledge the support of the Ministry of Science and Technology of Taiwan (MOST 106-2314-B-039-048, 107-2314-B-039-062-MY3 and 107-2636-B-009-001). We thank the editors at Tandem Editing for their careful copyediting.

Contributors RTL contributed to idea formulation, study design, data preparation, data analysis, reporting results, data interpretation and writing of the manuscript. SHL contributed to data analysis, reporting results, data interpretation and writing of the manuscript. MYC contributed to data analysis and reporting results.

Funding This work was supported by grants 106-2314-B-039-048, 107-2314-B-039-062-MY3 and 107-2636-B-009-001 from the Ministry of Science and Technology of Taiwan.

Competing interests None declared.

Patient consent for publication Not required.

Ethics approval This study has been approved by the Research Ethics Committee, China Medical University \& Hospital, Taichung, Taiwan (No. CMUH106-REC1-010). Our study involves comparison and analysis of variables at the population level (industry groups) rather than at the individual level. No personal data were handled.

Provenance and peer review Not commissioned; externally peer reviewed. Data availability statement Data are available in a public, open access repository. Open access This is an open access article distributed in accordance with the Creative Commons Attribution Non Commercial (CC BY-NC 4.0) license, which permits others to distribute, remix, adapt, build upon this work non-commercially, and license their derivative works on different terms, provided the original work is properly cited, appropriate credit is given, any changes made indicated, and the use is non-commercial. See: http://creativecommons.org/licenses/by-nc/4.0/.

\section{REFERENCES}

1. Yamauchi T, Yoshikawa T, Takamoto M, et al. Overwork-related disorders in Japan: recent trends and development of a national policy to promote preventive measures. Ind Health 2017;55:293-302.

2. Chang HH, Lin RT. Policy changes for preventing and recognizing overwork-related cardiovascular diseases in Taiwan: an overview. $J$ Occup Health;2019.

3. Tsai M-C, Nitta M, Kim S-W, et al. Working overtime in East Asia: convergence or divergence? J Contemp Asia 2016;46:700-22.

4. Bureau of Labor Insurance, Ministry of Labor, Taiwan. Annual reports. Ministry of labor 2006-2016. Available: http://www.bli.gov.tw/en/sub. aspx?a=A0cWbbyNSr8\%3d [Accessed 24 Feb 2018].

5. International Labour Organization. The prevention of occupational diseases. Switzerland: International Labour Organization, 2013.

6. Avendano M, Berkman LF, markets L. employment policies, and health. In: Berkman LF, Kawachi I, Glymour MM, eds. Social Epidemiology. 2nd edn. Oxford, United Kingdom: Oxford University Press, 2014: 182-233.

7. Berkman LF, Kawachi I, Theorell T. Working conditions and health. In: Berkman LF, Kawachi I, Glymour MM, eds. Social Epidemiology. 2nd edn. Oxford, United Kingdom: Oxford University Press, 2014: 153-81.
8. Viscusi WK. Structuring an effective occupational disease policy: victim compensation and risk regulation. Yale $J$ on Reg 1984;2:53-81.

9. Takala J. Eliminating occupational cancer. Ind Health 2015;53:307-9.

10. McCann D. Working time laws: a global perspective. Switzerland: International Labour Organization, 2005.

11. International Labour Organization. Minimum wage policy guide. Available: http://www.ilo.org/global/topics/wages/minimum-wages/ lang-en/index.htm [Accessed 30 Nov 2017].

12. Occupational Safety and Health Administration, Ministry of Labor, Taiwan. Guidelines for the recognition of cerebrovascular and cardiovascular diseases aggravated by occupations (excluding caused by trauma). 1991, 2004, 2010, 2016, 2018. Available: https:// www.osha.gov.tw/1106/1176/1185/1190/1195/ [Accessed 2 Feb 2019].

13. Lin R-T, Lin C-K, Christiani DC, et al. The impact of the introduction of new recognition criteria for overwork-related cardiovascular and cerebrovascular diseases: a cross-country comparison. Sci Rep 2017;7:167.

14. Imai K, Keele L, Tingley D. A general approach to causal mediation analysis. Psychol Methods 2010;15:309-34.

15. VanderWeele T. Explanation in Causal Inference: Methods for Mediation and Interaction. New York, United States: Oxford University Press, 2015.

16. Lin R-T, Chien L-C, Kawachi I. Nonlinear associations between working hours and overwork-related cerebrovascular and cardiovascular diseases (CCVD). Sci Rep 2018;8:9694.

17. Ministry of Labor, Taiwan. Labor statistics and databases. 2006-2017. Available: https://statfy.mol.gov.tw/statistic_DB.aspx [Accessed 17 Mar 2019].

18. Richiardi L, Bellocco R, Zugna D. Mediation analysis in epidemiology: methods, interpretation and bias. Int J Epidemiol 2013;42:1511-9.

19. MacKinnon DP. Introduction to Statistical Mediation Analysis. New York, United States: Routledge, 2008.

20. Agresti A. Categorical data analysis. Hoboken, New Jersey: United States: John Wiley \& Sons, 2013.

21. Tingley $\mathrm{D}$, Yamamoto $\mathrm{T}$, Hirose $\mathrm{K}$, et al. mediation : $R$ Package for Causal Mediation Analysis. J Stat Softw 2014;59:38.

22. Cheng Y, Du C-L, Hwang J-J, et al. Working hours, sleep duration and the risk of acute coronary heart disease: a case-control study of middle-aged men in Taiwan. Int J Cardiol 2014;171:419-22.

23. Liu $\mathrm{H}-\mathrm{C}$, Chen $\mathrm{C}-\mathrm{Y}$, Lee $\mathrm{C}$, et al. The health impact of misinterpreted flexicurity: an example of the amendments to the labor standard act. Taiwan J Public Health 2018;37:1-7.

24. Lin R, PH Y. Is Taiwan out of kilter with reality? CommonWealth Magazine 2017;616.

25. Lin R-T. Overwork management: from employee assistance to national policy changes. 2019 KIHA winter conference 13-15. Yeosu, Korea: Korean Industrial Hygiene Association (KIHA), 2019.

26. Park J, Kim Y, Cheng Y, et al. A comparison of the recognition of overwork-related cardiovascular disease in Japan, Korea, and Taiwan. Ind Health 2012;50:17-23.

27. Ministry of Health, Labour and Welfare, Japan. Act on promotion of preventive measures against Karoshi and other Overwork-related health disorders, 2014

28. Organisation for Economic Co-operation and Development. Average annual hours actually worked per worker. 2008-2017. Available: https://stats.oecd.org/Index.aspx?DataSetCode=ANHRS [Accessed 17 Mar 2019].

29. Bor J. Capitalizing on natural experiments to improve our understanding of population health. Am J Public Health 2016;106:1388-9.

30. Schwartz S. The fallacy of the ecological fallacy: the potential misuse of a concept and the consequences. Am J Public Health 1994;84:819-24.

31. Lin S-H, Young J, Logan R, et al. Parametric mediational g-formula approach to mediation analysis with time-varying exposures, mediators, and confounders. Epidemiology 2017;28:266-74.

32. Lin S-H, Young JG, Logan R, et al. Mediation analysis for a survival outcome with time-varying exposures, mediators, and confounders. Stat Med 2017;36:4153-66.

33. Vanderweele TJ, Vansteelandt S. Conceptual issues concerning mediation, interventions and composition. Stat Interface 2009;2:457-68.

34. VanderWeele TJ, Vansteelandt $\mathrm{S}$. Odds ratios for mediation analysis for a dichotomous outcome. Am J Epidemiol 2010;172:1339-48. 